\title{
Antisense RNA to ahpC, an oxidative stress defence gene involved in isoniazid resistance, indicates that AhpC of Mycobacterium bovis has virulence properties
}

\author{
Theresa Wilson, ${ }^{1}$ Geoffrey W. de Lisle, ${ }^{1}$ Jovita A. Marcinkeviciene, ${ }^{2}$ \\ John S. Blanchard ${ }^{2}$ and Desmond M. Collins'
}

\begin{abstract}
Author for correspondence: Theresa Wilson. Tel: +64 4528 6089. Fax: +64 45281380. e-mail: wilsont@agresearch.cri.nz
\end{abstract}

1 AgResearch, Wallaceville Animal Research Centre, PO Box 40063, Upper Hutt, New Zealand

2 Department of Biochemistry, Albert Einstein College of Medicine of Yeshiva University, Bronx NY 10461, USA

\begin{abstract}
Antisense RNA is a versatile tool for reducing gene expression. It was used to determine if ahpC, a gene that is involved in defence against oxidative stress and isoniazid (INH) resistance, is important for virulence of Mycobacterium bovis, a member of the Mycobacterium tuberculosis complex. Antisense RNA constructs of ahpC were made using different strength promoters in front of a reversed coding sequence of ahpC. These constructs were electroporated into a virulent wild-type $\boldsymbol{M}$. bovis strain and a moderately virulent INH-resistant $\boldsymbol{M}$. bovis strain that was catalase/peroxidase-negative. Down-regulation of protein synthesis occurred and this was visualized by immunoblotting. All strains containing antisense RNA were markedly less virulent than their parent strains in guinea pigs. $M$. bovis with an up-regulated ahpC gene was more resistant to cumene hydroperoxide than its parent strain, which had a wildtype ahpC promoter. These results agree with a model of INH resistance in which overexpression of AhpC compensates in some INH-resistant strains for loss of catalase/peroxidase by maintaining the ability to defend against oxidative stress mediated through organic peroxides. In addition, normal expression of AhpC is crucial for maintaining the virulence of wild-type $M$. bovis, which has normal catalase/peroxidase levels.
\end{abstract}

Keywords: antisense RNA, AhpC, virulence, Mycobacterium tuberculosis complex, oxidative stress

\section{INTRODUCTION}

The oxidative stress response of mycobacteria is an emerging research area that is linked to resistance to isoniazid (INH), one of the front-line drugs used in the treatment of human tuberculosis. INH-resistant strains of Mycobacterium tuberculosis appeared soon after INH treatment was initiated in 1952 and these had often lost virulence for guinea pigs and had a simultaneous loss of catalase activity (Middlebrook, 1954). Catalase detoxifies hydrogen peroxide which is generated by normal bacterial metabolism as well as by macrophages as part of the host's defence mechanisms. The $M$. tuberculosis complex, which includes Mycobacterium bovis, contains a single catalase enzyme which also has

Abbreviations: INH, isoniazid; TEA, triethanolamine. peroxidase activity and is encoded by kat $G$. Several lines of evidence support the theory that INH is a prodrug that requires activation by KatG (Johnsson \& Schultz, 1994; Basso et al., 1996). Once INH is activated it inhibits the biosynthesis of cell wall mycolic acids by directly inhibiting an enoyl-[acyl-carrier-protein] reductase encoded by inhA (Dessen et al., 1995; Quemard et al., 1995, 1996). Activated INH may also inhibit other enzymes of mycolic acid synthesis (Mdluli et al., 1996). Mutations which appear to confer lowlevel INH resistance have been identified in the coding sequence of inhA (Banerjee et al., 1994; Kapur et al., 1995), and more commonly in the inhA promoter (Musser et al., 1996; Rouse et al., 1995). However, one of the major means by which $M$. tuberculosis and $M$. bovis develop resistance to INH is by loss of functional KatG (Zhang \& Young, 1994; Heym et al., 1995). This leaves the organism more susceptible to damage from 
Table 1. Mycobacterial strains and integrating shuttle plasmids used in this study

\begin{tabular}{|c|c|c|}
\hline Strain/plasmid & Characteristics & Source/reference ${ }^{*}$ \\
\hline \multicolumn{3}{|l|}{ Strains } \\
\hline \multicolumn{3}{|l|}{ M. bovis } \\
\hline ATCC 35723 & Bovine isolate & ATCC \\
\hline ATCC 35728 & INH-resistant daughter strain of ATCC 35723 & ATCC \\
\hline ATCC 35729 & INH-resistant daughter strain of ATCC 35723 & ATCC \\
\hline WAg201 & New Zealand bovine isolate & Wilson et al. (1995) \\
\hline WAg405 & $\begin{array}{l}\text { INH-resistant daughter strain of WAg201, catalase-minus, no mutation in } \\
a b p C \text { promoter }\end{array}$ & Wilson et al. (1995) \\
\hline WAg420 & $\begin{array}{l}\text { INH-resistant daughter strain of ATCC } 35723 \text { (isolated in vitro on } 5 \mu \mathrm{g} \text { INH } \\
\mathrm{ml}^{-1} \text { ) }\end{array}$ & This work \\
\hline WAg421 & ATCC 35723 carrying $a b p C$ antisense RNA construct, pUHA244 & This work \\
\hline WAg422 & ATCC 35723 carrying $a h p C$ antisense RNA construct, pUHA245 & This work \\
\hline WAg423 & ATCC 35728 carrying $a h p C$ antisense RNA construct, pUHA244 & This work \\
\hline WAg424 & ATCC 35728 carrying $a h p C$ antisense RNA construct, pUHA245 & This work \\
\hline WAg427 & ATCC 35728 carrying $a h p C$ antisense RNA and kat $G$ construct, pUHA253 & This work \\
\hline \multicolumn{3}{|l|}{ M. tuberculosis } \\
\hline H37Rv & TMC 102 & TMC \\
\hline ATCC 35822 & INH-resistant daughter of $H 37 R v$ & ATCC \\
\hline \multicolumn{3}{|l|}{ Plasmids } \\
\hline pYUB178 & Integrating mycobacterial shuttle plasmid & Pascopella et al. (1994) \\
\hline pUHA244 & $\begin{array}{l}\text { pYUB178 carrying ATCC } 35723 a h p C \text { promoter in front of reversed coding } \\
\text { sequence of } a b p C\end{array}$ & This work \\
\hline pUHA245 & $\begin{array}{l}\text { pYUB178 carrying ATCC } 35822 a b p C \text { promoter in front of reversed coding } \\
\text { sequence of } a b p C\end{array}$ & This work \\
\hline pUHA253 & pUHA245 carrying a kat $G$ gene integrated into the $K p n I$ site & This work \\
\hline
\end{tabular}

*ATCC, American Type Culture Collection; TMC, Trudeau Mycobacterial Collection.

hydrogen peroxide and other toxic lipid peroxides. While this does not inhibit growth of the organisms in mycobacterial culture media, some catalase-minus INHresistant strains are no longer virulent, probably because they require a functional KatG for protection against the oxidative burst of macrophages. Restoration of KatG activity to M. tuberculosis (Zhang et al., 1993) or M. bovis (Wilson et al., 1995) restores INH sensitivity and in the case of $M$. bovis has been shown to restore virulence for guinea pigs (Wilson et al., 1995).

AhpC, a putative alkyl hydroperoxide reductase, appears to be produced constitutively in wild-type strains of the M. tuberculosis complex and its level does not respond to oxidative stress (Sherman et al., 1995). In many bacteria, the response to oxidative stress is determined by a central regulator, OxyR, which controls the transcription of genes such as kat $G$ and $a b p C$ (Christman et al., 1985; Storz et al., 1989). Although the oxyR gene is functional in Mycobacterium leprae and Mycobacterium avium, it is inactive in M. tuberculosis and M. bovis (Deretic et al., 1995; Dhandayuthapani et al., 1996; Sherman et al., 1995). Insertional inactivation of ahpC in Mycobacterium smegmatis increased the susceptibility of this species to INH (Zhang et al., 1996) and increased production of AhpC in M. smegmatis decreased its susceptibility (Dhandayuthapani et al., 1996). This correlation with the level of INH sus- ceptibility suggested that $\mathrm{AhpC}$ might have been detoxifying the active form of INH produced by KatG. However, a similar effect with AhpC has not been shown in strains of the M. tuberculosis complex.

Some INH-resistant strains of the $M$. tuberculosis complex have mutations in the promoter of $a b p C$. These mutations in the $a b p C$ promoter lead to increased expression of $\mathrm{AhpC}$ as determined by reporter assays and immunoblotting (Wilson \& Collins, 1996; Heym et al., 1997; Sherman et al., 1996). It appears that to survive attack from both the host and the presence of INH, there has been a selection for strains that have lost catalase/ peroxidase activity and gained a compensating increase in expression of AhpC.

After unsuccessful attempts to inactivate the $a b p C$ gene in $M$. bovis by allelic exchange, we developed an antisense RNA approach to reduce the levels of AhpC. Bacteria and phage use endogenous antisense RNA transcripts as an efficient and specific means of regulating gene expression of several biological functions (Wagner \& Simons, 1994). Antisense RNA is increasingly being used as a research tool for reducing gene expression. It may be especially useful in situations where it is lethal to inactivate a gene but reduction of the level of protein might be tolerated. With the use of this approach, together with AhpC immunoblotting, we investigated the role of $\mathrm{AhpC}$ in a wild-type strain of $M$. 
bovis with a normal $a b p C$ promoter and in an INHresistant strain of $M$. bovis with an up-regulated $a b p C$ promoter.

\section{METHODS}

Mycobacterial strains, growth conditions and catalase activity. Mycobacterial strains and plasmids used in this study are given in Table 1 . Strains of $M$. bovis were routinely cultured in Middlebrook 7H9 (Difco) liquid medium supplemented with albumin/glucose (Difco), 0.05\% Tween 80 and $0.4 \%$ sodium pyruvate and in Middlebrook 7H11 (Difco) solid medium supplemented with albumin/glucose and $0.4 \%$ sodium pyruvate. Strains were electroporated by using the method of Wards \& Collins (1996) in which slow-growing mycobacteria are washed at room temperature and electroporated at $37^{\circ} \mathrm{C}$. After electroporation, M. bovis was cultured on solid medium containing $15 \mu \mathrm{g}$ kanamycin $\mathrm{ml}^{-1}$. ATCC 35728 used in this study was originally isolated as an INHresistant strain from a rabbit that was inoculated with ATCC 35723 and treated with INH (Steenken \& Wolinsky, 1955). WAg420 was isolated by selecting colonies of ATCC 35723 for

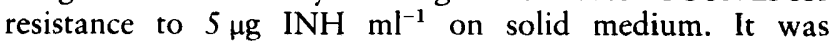
subsequently determined to be catalase-negative and to have an MIC for INH of $>50 \mu \mathrm{g} \mathrm{ml}^{-1}$ by using previously described methods (Wilson et al., 1995).

Purification of AhpC. The coding sequence of $a b p C$ was amplified using primers 5 'TTAATTCCATATGCCACTGCTAACCATTGG and 5'CTCGGATCCTTAGGCCGAAGCCTTGAGGA, digested with BamHI and NdeI, directionally cloned into pET3a (Novagen), and electroporated into Escherichia coli BL21. A culture was grown overnight at $34^{\circ} \mathrm{C}$ and expression of AhpC was induced by IPTG. After $2 \mathrm{~h}$, the bacteria were pelleted and suspended in $50 \mathrm{mM}$ triethanolamine $/ \mathrm{HCl}$ buffer, $\mathrm{pH} 7.8$ (TEA), containing protease inhibitors (2.3 mg leupeptin $\mathrm{l}^{-1} ; 52 \mathrm{mg}$ 1-chloro-3-tosylamido7-amino-2-heptadone $\mathrm{l}^{-1} ; 20 \mathrm{mg}$ soybean trypsin inhibitor $\mathrm{l}^{-1}$; $1.6 \mathrm{mg}$ aprotinin $\mathrm{I}^{-1} ; 1.1 \mathrm{mg}$ pepstatin $\mathrm{l}^{-1} ; 36.2 \mathrm{mg} \mathrm{PMSF}^{-1}$; and $1 \mathrm{mg}$ lysozyme $\left.\mathrm{ml}^{-1}\right)$. Cells were disrupted by sonication, the cell debris was pelleted and nucleic acids were precipitated by the addition of streptomycin sulphate to $1 \%$. The supernatant was dialysed against TEA and loaded onto a FastFlow Q Sepharose (Pharmacia) column. Proteins were eluted using a $0-1 \mathrm{M} \mathrm{NaCl}$ gradient, and fractions containing the induced $25 \mathrm{kDa} \mathrm{AhpC}$ were pooled and loaded onto a Superdex 200 column. Eluted fractions containing the $25 \mathrm{kDa}$ band were pooled and applied to a $1 \times 10 \mathrm{~cm}$ Mono $Q$ (Pharmacia) column. Proteins were eluted with a $0-0.5 \mathrm{M}$ $\mathrm{NaCl}$ gradient and the desired fractions were pooled. The pool was applied to a Sephadex G-75 column and fractions containing the $25 \mathrm{kDa}$ protein were pooled to yield $16 \mathrm{mg}$ $95 \%$ pure protein. Antiserum against this purified AhpC was raised in female New Zealand White rabbits by intramuscular injection of $250 \mu \mathrm{g}$ in Freund's incomplete adjuvant (Difco) followed by a subcutaneous booster of $250 \mu \mathrm{g}$ after 3 weeks and a second booster after another 2 weeks. The rabbits were bled 2 weeks later and serum was collected.

Sensitivity growth curves. Sensitivity of $M$. bovis strains to inhibitory compounds was determined by adding $0 \cdot 1 \mathrm{ml}$ of a mid-exponential-phase culture in Tween-albumin broth (Kent \& Kubica, 1985) to $5 \mathrm{ml}$ amounts of the same broth which contained increasing concentrations of either cumene hydroperoxide (dissolved in DMSO) or hydrogen peroxide. The $\mathrm{OD}_{600}$ was measured after $4 \mathrm{~d}$ (Ultrospec 2000 spectrophotometer; Pharmacia Biotechnology) and the percentage

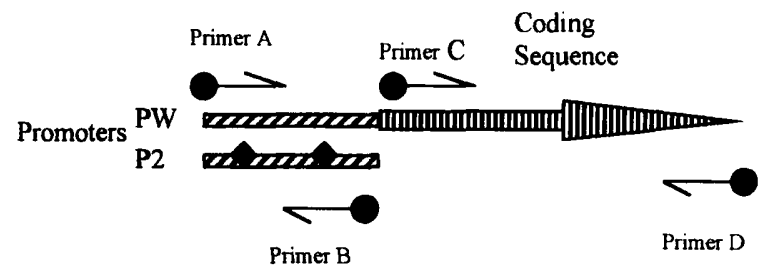

PCR separately with primers $A, B$, and $C, D$ Digest products with $\mathrm{Bam} \mathrm{HI}$ Ligate

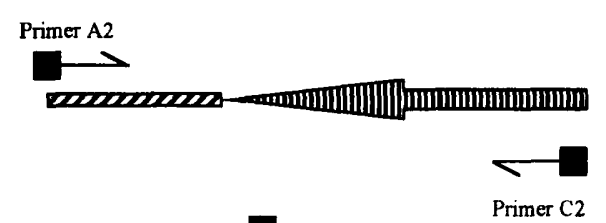

PCR with primers $\mathrm{A} 2$ and $\mathrm{C} 2$

Digest with $B g / I I$

Ligate into pYUB178

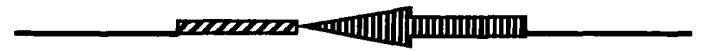

pUHA244

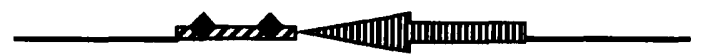

pUHA245

Fig. 1. Schematic representation of the experimental procedure for making antisense RNA constructs. PW, ahpC promoter from ATCC 35723; P2, ahpC promoter from ATCC 35822; mutations in the ahpC promoter;,$B a m H I$ sites; $\square, B g / l l$ sites.

survival was calculated. A few samples were plated for c.f.u. to verify that $\mathrm{OD}_{600}$ correlated to c.f.u.

Antisense constructs. The antisense constructs were generated as summarized in Fig. 1. The $a b p C$ promoters used were a wild-type promoter (PW) from ATCC 37523 and a promoter with two mutations (P2) from ATCC 35822. PW and P2 were amplified separately with primers A (5'CTCGGATCCACTGCTGAACCACTGCTTTGC) and B (5'CTCGGATCCGACTCTCCTCATCATCAATGC), the $a b p C$ coding sequence was amplified with primers $C\left(5^{\prime}\right.$ CTCGGATCCTCATGCCACTGCTAACCATTG) and D (5'CTCGGATCCTTAGGCCGAAGCCTTGAGGAG) and all PCR products were digested at the $B a m H I$ sites that had been incorporated in the primers. PW and P2 were ligated separately to the coding sequence of $a b p C$ and an aliquot of each ligation mix was subjected to PCR amplification with primers A2 (5'GGAAGATCTACTGCTGAACCACTGCTT) and C2 (5'GGAAGATCTATGCCACTGCTAACCATT), which bound at similar positions to primers $A$ and $C$ but incorporated $B g l \mathrm{II}$ sites. The mixture was digested with $B g l I I$ and ligated into the $B c l$ I cloning site of the integrating shuttle vector pYUB178. The ligation mixtures were electroporated into $E$. coli and kanamycin-resistant clones containing the expected $800 \mathrm{bp}$ antisense inserts were selected. The two antisense constructs, pUHA244 for PW and pUHA245 for P2, were electroporated into ATCC 35723 and ATCC 35728. Kanamycin-resistant colonies were picked into liquid medium and after being cultured to mid-exponential phase their proteins were extracted (Wilson et al., 1995). A third antisense construct was 
made by ligating a $4.5 \mathrm{~kb} \mathrm{KpnI} \mathrm{fragment} \mathrm{containing} \mathrm{kat} G$ into the KpnI site of pUHA245 to form pUHA253. This plasmid was electroporated into ATCC 35728.

Immunoblotting. Equal amounts of protein (determined by using a Bio-Rad kit with BSA as the protein standard) were separated on a $12 \%$ SDS-PAGE gel and transferred to nylon (Zeta-Probe; Bio-Rad) at $50 \mathrm{~V}$ for $45 \mathrm{~min}$ in $3 \mathrm{mM} \mathrm{Na}_{2} \mathrm{CO}_{3}$, $10 \mathrm{mM} \mathrm{NaHCO}_{3}$, pH 9.9, containing $20 \%$ (v/v) methanol. The nylon was blocked with $5 \%$ skim milk powder in Tris $/ \mathrm{NaCl}$ buffer $(20 \mathrm{mM}$ Tris, $\mathrm{pH} 7.5,500 \mathrm{mM} \mathrm{NaCl}$ ) for $1 \mathrm{~h}$, incubated with anti-AhpC overnight at a $1: 100$ dilution, washed in Tris/ $\mathrm{NaCl}$ buffer, incubated with goat anti-rabbit alkaline phosphatase conjugate $(1: 2000$ dilution) for $4 \mathrm{~h}$, washed again in Tris/ $\mathrm{NaCl}$ buffer and developed using chloronaphthol solution $(0.015 \mathrm{~g}$ chloronaphthol dissolved in

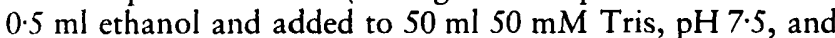
$0.06 \%$ hydrogen peroxide).

Southern blotting. DNA was isolated from $M$. bovis strains (van Soolingen et al., 1991) and digested with PstI overnight. DNA fragments were separated on a $1 \%$ agarose gel, transferred to nylon (Zetaprobe; Bio-Rad) and probed using ${ }^{32}$ P-labelled DNA.

Determination of virulence for guinea pigs. The virulence of M. bovis strains was assessed in female Duncan-Hartley guinea pigs, using a method described previously (Wilson et al., 1995). Each strain was inoculated at $10^{6}$ c.f.u. into three guinea pigs which were housed isolated in a biohazard animal cage. All animals were skin tested with bovine purified protein derivative before inoculation and again before being killed 8 weeks later. The assessment of virulence was based on the presence of visible and microscopic lesions of tuberculosis and numbers of organisms present in the spleen. M. bovis was isolated from guinea pig spleens by homogenization of half the spleen with $20 \mathrm{ml}$ water for $1 \mathrm{~min}$. This was filtered through sterile cheesecloth and centrifuged at $3500 \mathrm{~g}$ for $20 \mathrm{~min}$. The pellet was resuspended in $0.5 \mathrm{ml}$ water and aliquots were plated onto Middlebrook 7H11 medium supplemented with

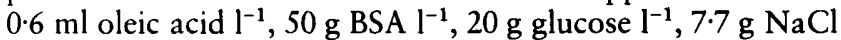
$\mathrm{I}^{-1}, 0 \cdot 4 \%$ sodium pyruvate, $0 \cdot 5 \%$ lysed sheep red blood cells, $10 \%$ bovine serum, $10 \mu \mathrm{g}$ fungizone $\mathrm{ml}^{-1}, 200 \mathrm{IU}$ polymyxin $\mathrm{B}$ sulphate, $100 \mu \mathrm{g}$ ticarcillin $\mathrm{ml}^{-1}$ and $10 \mu \mathrm{g}$ trimethoprim $\mathrm{ml}^{-1}$. All animal work was approved by the institution's Animal Ethics Committee.

\section{RESULTS AND DISCUSSION}

\section{Overexpression of AhpC}

The coding sequence of $a h p C$ was ligated into an expression vector and $\mathrm{AhpC}$ was expressed and purified by column chromatography. Antiserum was raised and probed against a Western blot of protein extracts from M. tuberculosis and M. bovis strains (Fig. 2). Strains with a wild-type $a h p C$ promoter had barely detectable levels of $\mathrm{AhpC}$. The promoters from the $a$ hp $C$ gene had previously been studied using a reporter assay (Wilson \& Collins, 1996) and the immunoblot verified the trends previously identified. M. tuberculosis strain ATCC 35822 , which has two mutations in the ahpC promoter, overexpressed AhpC by 20-30-fold, while M. bovis ATCC 35728 with one mutation overexpressed by 10-15-fold compared to their respective parent strains. Another INH-resistant $M$. bovis strain (WAg405) with no mutations in $a b p C$ had no detectable increase in

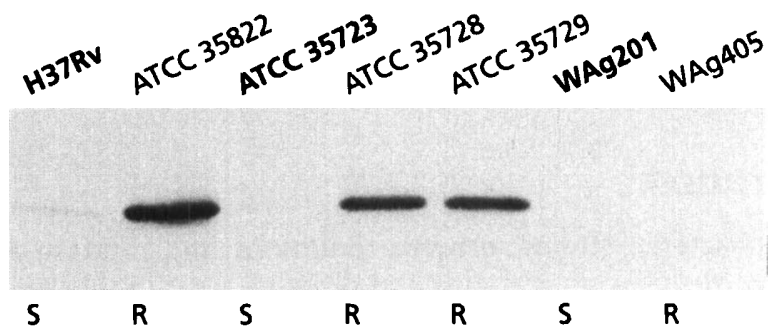

Fig. 2. Immunoblot analysis of protein extracts $(20 \mu \mathrm{g})$ from strains of $M$. tuberculosis and $M$. bovis, probed with polyclonal antiserum to AhpC. Parent strains are in bold, with their daughter strains shown to the right. $S$ and $R$ denote sensitivity or resistance to INH. All resistant strains had an MIC for INH of $>50 \mu \mathrm{g} \mathrm{ml}^{-1}$.

AhpC expression. Mutations in the promoter have been found in $13 \%$ of INH-resistant clinical strains of $M$. tuberculosis (Heym et al., 1997; Telenti et al., 1997), and mutations in the coding sequence have also been reported although their functional significance is unknown (Sreevatsan et al., 1997). It was proposed by us and others that selection for up-regulation of $a b p C$ occurred when an organism became INH-resistant through loss of KatG activity and that AhpC might be compensating for this loss (Wilson \& Collins, 1996; Sherman et al., 1996; Heym et al., 1997).

Overexpression of $\mathrm{AhpC}$ was found to confer resistance to both hydrogen peroxide and the organic peroxide cumene hydroperoxide (Fig. 3). The parent ATCC 35723 (wild-type KatG and AhpC) was resistant to hydrogen peroxide but sensitive to cumene hydroperoxide; its in vitro-derived daughter, WAg420 (KatG-minus, AhpC wild-type), was very sensitive to hydrogen peroxide and sensitive to cumene hydroperoxide, while the in vivoderived daughter, ATCC 35728 (KatG-minus, AhpC overexpressed), showed moderate resistance to both hydrogen peroxide and cumene hydroperoxide. This indicates that $\mathrm{AhpC}$ may play a role in protecting against oxidative stress.

\section{Antisense RNA reduces production of AhpC}

We attempted unsuccessfully to inactivate $a b p C$ by allelic exchange with a fragment of DNA containing a drug-resistance marker interrupting the $a h p C$ gene (data not shown) in a similar way to that used to interrupt the ure C gene (Reyrat $e t$ al., 1995). This lack of success may have been either due to $a b p C$ being an essential gene or may be a reflection of the difficulty in carrying out double homologous recombination in wild-type $M$. bovis. Based on the rationale that it might be lethal to inactivate $a b p C$ but that reduction of the level of $\mathrm{AhpC}$ might be tolerated, we chose to reduce the level of $\mathrm{AhpC}$ by using antisense RNA.

An antisense RNA approach was designed so that the amount of free mRNA encoding AhpC would be reduced to two different extents resulting in reduced 


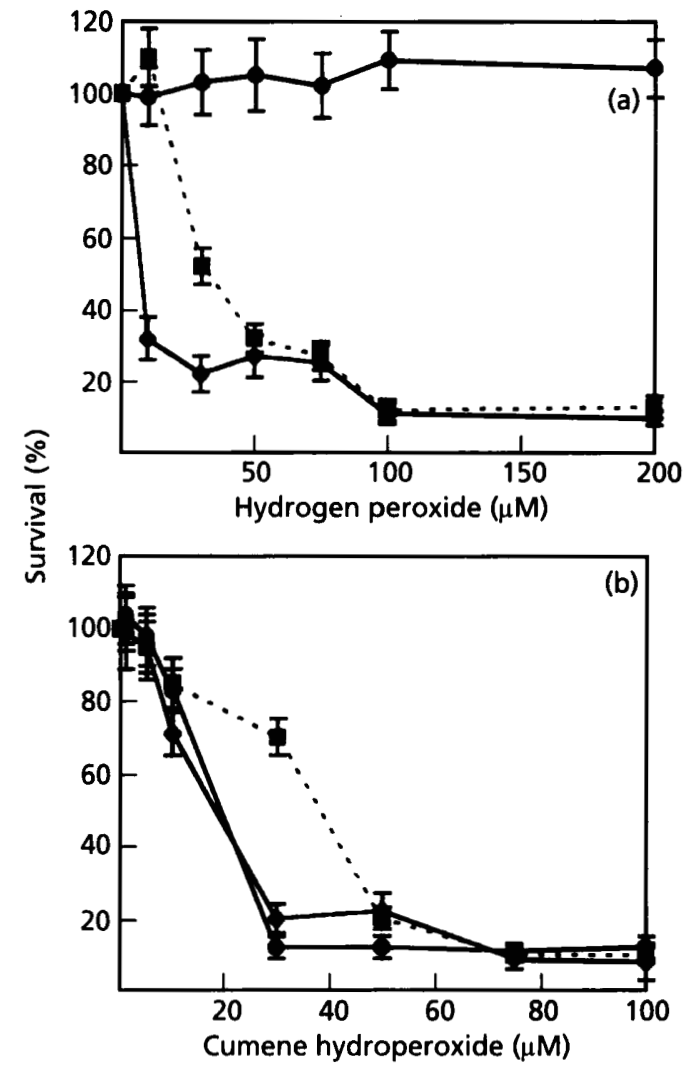

Fig. 3. Growth sensitivity curves for $M$. bovis strains at different concentrations of hydrogen peroxide (a) and cumene hydroperoxide (b). O, ATCC 35723; ם, ATCC 35728; $\bullet$, WAg420.

levels of AhpC. Two antisense RNA constructs were made using a wild-type promoter from the INHsensitive strain ATCC 35723 and a promoter from the INH-resistant strain ATCC 35822 that has two mutations which effect a large increase in AhpC levels (Fig. 2). These promoters were ligated in front of a reversed $a h p C$ gene as shown diagrammatically in Fig. 1. The two constructs were electroporated into $M$. bovis strains ATCC 35723 and ATCC 35728. Integration of the constructs into the chromosome was confirmed by Southern blot analysis. The levels of AhpC in the recombinants and parent strains were determined by probing Western blots of protein extracts with antiserum to AhpC (Fig. 4). The level of AhpC in ATCC 35728 was at least 10 -fold higher than in its parent ATCC 35723 , in which AhpC was barely detected. Reduction of the level of AhpC occurred in ATCC 35728 containing the antisense RNA with the wild-type promoter (WAg423) and the level of AhpC was lower still in the ATCC 35728 recombinant containing the antisense RNA with the up-regulated promoter (WAg424). No AhpC was detected on the Western blot with either of the antisense RNA constructs in ATCC 35723. Hence we could determine that the antisense RNA constructs had integrated into the chromosome and were reducing significantly the levels of AhpC.

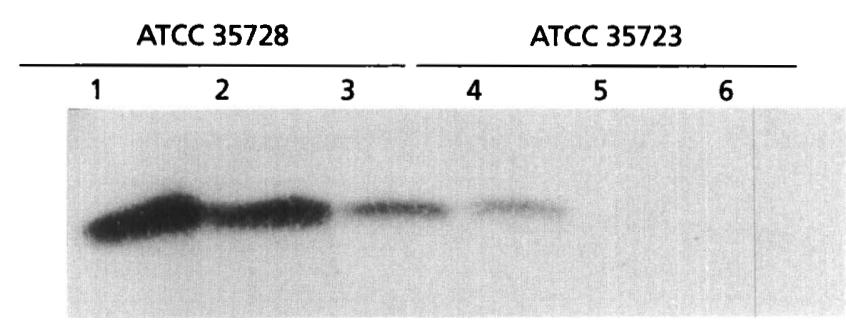

Fig. 4. Immunoblot analysis of protein extracts $(20 \mu \mathrm{g})$ from strains of $M$. bovis, probed with polyclonal antiserum to AhpC. Control extracts of the two strains ATCC 35728 and ATCC 35723 (lanes 1 and 4 ) are to the left of their respective recombinant daughter strains which contained the two different antisense RNA constructs. Lanes: 2, WAg423 containing the antisense construct with the wild-type promoter; 3, WAg424 containing the antisense construct with the promoter with two mutations; 5, WAg421 containing the antisense construct with the wildtype promoter; 6, WAg422 containing the antisense construct with the promoter with two mutations.

\section{Antisense RNA constructs in $M$. bovis strains greatly reduced their virulence}

The effect on virulence in guinea pigs of reducing the level of AhpC in M. bovis was assessed for the parent and antisense-containing strains on the basis of the presence or absence of gross and histopathological lesions in spleen, liver and lung tissues and on spleen c.f.u. (Table 2). The parent strain ATCC 35723 was virulent and multiple lesions were observed in the spleen and liver of all animals, while the antisense RNA recombinants (WAg421 and WAg422) caused no visible lesions and relatively few organisms could be cultured from the spleen. A reduction in virulence was also observed for the antisense recombinants of the INHresistant ATCC 35728. ATCC 35728 itself was moderately virulent while the recombinant with the upregulated promoter in front of the antisense RNA (WAg424) was assessed as avirulent.

Although immunoblotting showed that the levels of $\mathrm{AhpC}$ in WAg424 were similar to those in ATCC 35723, WAg424 was avirulent while ATCC 35723 was virulent. The only major difference known between these two strains was in their catalase/peroxidase activity encoded by $k a t G$. Thus we propose that, in moderately virulent strains such as ATCC 35728 which have no detectable KatG activity and which have gained an up-regulation mutation of their $a b p C$ gene, the overexpression of AhpC partly compensates for the loss of virulence associated with loss of KatG activity.

While the above experiments clearly showed that incorporating antisense RNA to $a b p C$ into $M$. bovis reduced the level of $\mathrm{AhpC}$, the ability of this antisense RNA to reduce the virulence of $M$. bovis might not have been due to its effect on AhpC but to some other unforeseen effect such as titrating out an unknown regulatory factor. To rule out this possibility, an integrating plasmid was made which contained both an element producing antisense RNA to $a b p C$ (with an up- 
Table 2. Pathology of guinea pigs which had been subcutaneously inoculated with $10^{6}$ c.f.u. and killed 8 weeks later

\begin{tabular}{|c|c|c|c|c|c|c|c|c|}
\hline \multirow[t]{2}{*}{ Strain } & \multirow[t]{2}{*}{ Guinea pig } & \multicolumn{3}{|c|}{ Gross pathology* } & \multicolumn{3}{|c|}{ Histopathology $\dagger$} & \multirow{2}{*}{$\frac{\text { Culture } \ddagger}{\begin{array}{c}\text { Spleen } \\
\text { (c.f.u.) }\end{array}}$} \\
\hline & & Spleen & Liver & Lung & Spleen & Liver & Lung & \\
\hline \multirow[t]{3}{*}{ ATCC 35723} & 1 & Yes & Yes & Yes & +++ & ++ & + & $20 \times 10^{3}$ \\
\hline & 2 & Yes & Yes & No & +++ & ++ & - & $9 \times 10^{3}$ \\
\hline & 3 & Yes & Yes & No & +++ & ++ & - & $12 \times 10^{3}$ \\
\hline \multirow[t]{3}{*}{ WAg421 } & 1 & No & No & No & - & - & - & $<20$ \\
\hline & 2 & No & No & No & - & - & - & 20 \\
\hline & 3 & Yes & No & No & + & - & - & 30 \\
\hline \multirow[t]{3}{*}{ WAg422 } & 1 & No & No & No & - & - & - & 20 \\
\hline & 2 & Yes & No & No & + & - & - & 300 \\
\hline & 3 & No & No & No & - & - & - & 20 \\
\hline \multirow{3}{*}{ ATCC 35728} & 1 & Yes & No & No & ++ & - & - & 470 \\
\hline & 2 & Yes & No & No & ++ & - & - & 530 \\
\hline & 3 & Yes & Yes & No & ++ & ++ & - & $9 \times 10^{3}$ \\
\hline \multirow{3}{*}{ WAg423 } & 1 & No & No & No & + & - & - & 320 \\
\hline & 2 & No & No & No & - & - & - & $<20$ \\
\hline & 3 & No & No & No & + & - & - & 520 \\
\hline \multirow[t]{3}{*}{ WAg424 } & 1 & No & No & No & - & - & - & $<20$ \\
\hline & 2 & No & No & No & - & - & - & $<20$ \\
\hline & 3 & No & No & No & - & - & - & $<20$ \\
\hline \multirow[t]{3}{*}{ WAg427 } & 1 & Yes & Yes & No & +++ & +++ & - & $44 \times 10^{3}$ \\
\hline & 2 & Yes & Yes & No & ++ & ++ & - & $34 \times 10^{3}$ \\
\hline & 3 & Yes & Yes & Yes & +++ & ++ & ++ & $82 \times 10^{3}$ \\
\hline
\end{tabular}

*Visible lesions observed.

+- , No evidence of lesions;,,,+++++ degree of granuloma formation.

$\neq c$.f.u. values were corrected to represent the entire spleen.

regulated $a h p C$ promoter) and a functional $k a t G$ gene (pUHA253). This construct was electroporated into ATCC 35728 to produce a strain (WAg427) that was $k a t G$-positive (as shown by the production of bubbles when hydrogen peroxide was dropped onto a colony) and, because of the antisense element, would be expected to have a level of AhpC similar to that in WAg424. W Ag427 was found to be virulent for guinea pigs (Table 2). So we had taken ATCC 35728 that was moderately virulent, reduced its virulence by reducing the expression of AhpC, and then been able to restore the organism to full virulence by restoring KatG activity. We conclude that the reduction in virulence due to the antisense RNA is a result of its action in reducing the level of AhpC and not because it has some other non-specific effect. It also appears from this experiment that the moderate virulence of ATCC 35728 is because of its lack of a functional $k a t G$ gene.

$\mathrm{AhpC}$ also appears to perform a detoxification function that is independent of KatG. ATCC 35723, a virulent strain of $M$. bovis with wild-type levels of both KatG and $\mathrm{AhpC}$, lost virulence in the presence of both levels of antisense RNA, indicating that the organism could not remain virulent with less than normal constitutive expression of AhpC. It should be noted that loss of virulence and a reduced level of $\mathrm{AhpC}$ were the only phenotypic changes observed in the antisense-containing recombinants of ATCC 35723 and these recombinants had similar in vitro growth to their parent strain.

\section{Antisense RNA revertants isolated from guinea pigs}

M. bovis colonies isolated from guinea pig spleens after the 8 week virulence experiment were analysed by Southern blotting and hybridization with a probe of the vector pYUB178 (Fig. 5). This analysis revealed that DNA of colonies from some animals (Fig. 5a, lanes 2, 3, 6, 7 and 9) no longer hybridized to the vector that had been integrated even though there was an adequate amount of DNA in each of these lanes (Fig. 5b). In the results shown in Fig. 5 for four animals inoculated with either WAg421 or WAg423, three of the animals contained these revertants. We also saw this evidence of reversion in animals inoculated with the other antisensecontaining $M$. bovis recombinants $\mathrm{WAg} 422$ and WAg424 (data not shown). All strains that were used for inoculation into guinea pigs came from single colony isolates that contained an integrated pYUB178 construct. Previously, we have made integrated pYUB178 recombinants with several different constructs and have never observed reversion of the strains under in vitro or 


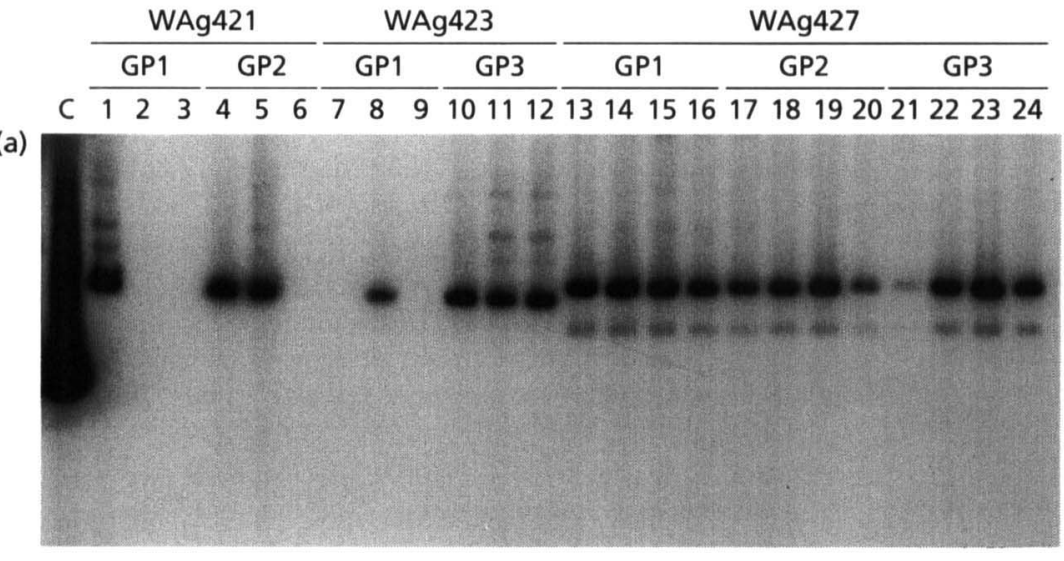

(b)

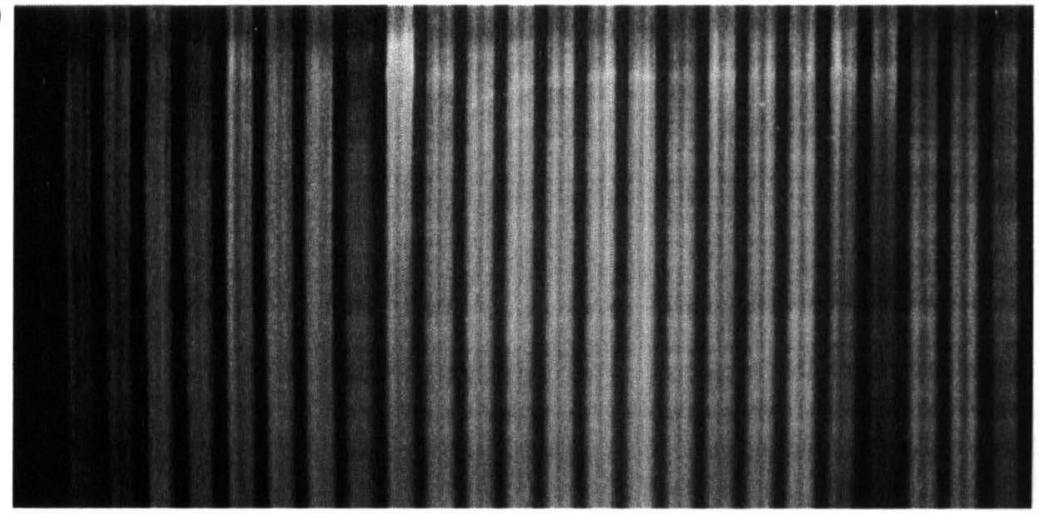

Fig. 5. Southern blot data for DNA from strains isolated from guinea pig (GP) spleens at the end of the virulence experiment. (a) Southern blot hybridization after probing with ${ }^{32} \mathrm{p}$-labelled integration vector (pYUB178). (b) Photograph of the gel before transferring to nylon. in vivo conditions (Collins et al., 1995; Wilson et al., 1995). These results indicate that there was a selective pressure in animals for these strains to lose the antisense constructs and regain their natural virulence. However, no evidence of reversion was found in any of the 12 samples of DNA from colonies isolated from three different animals inoculated with WAg427 (antisense plus kat G) (Fig. 5). In this case, the antisense RNA has reduced the levels of $\mathrm{AhpC}$ from high to wild-type levels and this in the presence of a functional kat $G$ enabled WAg427 to be virulent. It therefore appears that in the presence of wild-type levels of activity of KatG and AhpC there was no selective advantage for the antisense construct to be lost.

In an alternative approach to investigate the role of AhpC in virulence, INH-resistant strains of $M$. $t u$ berculosis were produced in vitro and it was found that a strain that had lost KatG activity and acquired an upregulated $a b p C$ was attenuated in mice (Heym et al., 1997). Having an up-regulated $a b p C$ in that strain did not increase virulence. While the results of this mouse experiment contrast with our present study this may be explained by a number of factors, including the different overall genetic composition of the strains used in the two studies, the different animal models used and the different ways in which strains were derived. The major difference between INH-resistant strains derived in vitro and those isolated clinically is their mode of selection. If the strain is selected in a host that is being treated with $\mathrm{INH}$, there is a dual selective pressure to develop INH resistance and to cope with the host defence mechanisms, including the oxidative challenge of the macrophage. It is possible that in these clinical strains derived in vivo, another as yet unknown genetic change may be compensating for the loss of that part of the KatG function that an overexpressed AhpC cannot fully replace.

This study has shown the utility of antisense RNA technology in investigation of mycobacterial virulence. The recent expression of antisense RNA to alpha toxin to attenuate Staphylococcus aureus confirms the general usefulness of such approaches for studying bacterial virulence (Kernodle et al., 1997). The wider versatility of antisense RNA methods for mycobacterial studies has been demonstrated by the creation of histidine auxotrophs of M. smegmatis (Parish \& Stoker, 1997) and by the use of antisense oligodeoxynucleotide phosphorothioates as antimycobacterial agents against drug-resistant M. smegmatis (Rapaport et al., 1996). The main finding of this study is that AhpC plays an important role in the virulence of both wild-type and INH-resistant strains of M. bovis and that overexpression of $\mathrm{AhpC}$ can compensate for the loss of catalase/peroxidase activity that occurs in some INH-resistant strains.

\section{ACKNOWLEDGEMENTS}

We thank Dr W. R. Jacobs for supplying pYUB178 and for encouragement of this work. The work was supported by the New Zealand Foundation for Research Science and Technology contract C10 626 (for T. W., G. W. de L., D. M.C.) and 
the National Institutes of Health GM33449 (for J.A.M. and J.S.B.).

\section{REFERENCES}

Banerjee, A., Dubnau, E., Quemard, A., Balasubramanian, V., Sun Um, K., Wilson, T., Collins, D., de Lisle, G. \& Jacobs, W. R. (1994). $\operatorname{inh} A$, a gene encoding a target for isoniazid and ethionamide in Mycobacterium tuberculosis. Science 263, 227-230.

Basso, L. A., Zheng, R. \& Blanchard, J. S. (1996). Kinetics of inactivation of WT and C243S mutant of Mycobacterium tuberculosis enoyl reductase by activated isoniazid. J Am Chem Soc 118, 11301-11302.

Christman, M. F., Morgan, R. W., Jacobson, F. S. \& Ames, B. N. (1985). Positive control of a regulon for defences against oxidative stress and some heat-shock proteins in Salmonella typhimurium. Cell 41, 753-762.

Collins, D. M., Kawakami, R. P., de Lisle, G. W., Pascopella, L., Bloom, B. R. \& Jacobs, W. R. (1995). Mutation of the principal sigma factor causes loss of virulence in a strain of the Mycobacterium tuberculosis complex. Proc Natl Acad Sci USA 92, 8036-8040.

Deretic, V., Phillip, W., Dhandayuthapani, S., Mudd, M. H., Curcic, R., Garbe, T., Heym, B., Via, L. E. \& Cole, S. T. (1995). Mycobacterium tuberculosis is a natural mutant with an inactivated oxidative-stress regulatory gene: implications for sensitivity to isoniazid. Mol Microbiol 17, 889-900.

Dessen, A., Quemard, A., Blanchard, J. S., Jacobs, W. R. \& Sacchettini, J. C. (1995). Crystal structure and function of the isoniazid target of Mycobacterium tuberculosis. Science 267, 1638-1641.

Dhandayuthapani, S., Zhang, Y., Mudd, M. H. \& Deretic, V. (1996). Oxidative stress response and its role in sensitivity to isoniazid in mycobacteria: characterization and inducibility of $a b p C$ by peroxides in Mycobacterium smegmatis and lack of expression in M. aurum and M. tuberculosis. J Bacteriol 178, 3641-3649.

Heym, B., Alzara, P., Honore, N. \& Cole, S. T. (1995). Missense mutations in the catalase-peroxidase gene, $k a t G$, are associated with isoniazid resistance in Mycobacterium tuberculosis. Mol Microbiol 15, 235-245.

Heym, B., Stavropoulos, E., Honore, N., Domenechi, P., SaintJoanis, B., Wilson, T., Collins, D. M., Colston, M. J. \& Cole, S. T. (1997). Effects of overexpression of the alkyl hydroperoxide reductase $\mathrm{AhpC}$ on the virulence and isoniazid resistance of Mycobacterium tuberculosis. Infect Immun 65, 1395-1401.

Johnsson, K. \& Schultz, P. G. (1994). Mechanistic studies of the oxidation of isoniazid by the catalase peroxidase from $\mathrm{MycO}$ bacterium tuberculosis. J Am Chem Soc 116, 7425-7426.

Kapur, V., Li, L. L., Hamrick, M. R. \& 10 other authors (1995). Rapid Mycobacterium species assignment and unambiguous identification of mutations associated with antimicrobial resistance in Mycobacterium tuberculosis by automated DNA sequencing. Arch Pathol Lab Med 119, 131-138.

Kent, P. T. \& Kubica, G.P. (1985). Public Health Mycobacteriology, A Guide for the Level III Laboratory. Atlanta, GA: US Department of Health and Human Services, Centers for Disease Control.

Kernodle, D. S., Voladri, R. K. R., Menzies, B. E., Hager, C. C. \& Edwards, K. M. (1997). Expression of an antisense bla fragment in Staphylococcus aureus reduces alpha-toxin production in vitro and attenuates lethal activity in a murine model. Infect Immun 65, 179-184.
Mdluli, K., Sherman, D. R., Hickey, M. J., Kreiswirth, B. N., Morris, S., Stover, C. K. \& Barry, C. E. (1996). Biochemical and genetic data suggest that InhA is not the primary target for activated isoniazid in Mycobacterium tuberculosis. J Infect Dis 174, 1085-1090.

Middlebrook, G. (1954). Isoniazid resistance and catalase activity of tubercle bacilli. Am Rev Tuberc 69, 471-472.

Musser, J. M., Kapur, V., Williams, D. L., Kreiswirth, B. N., van Soolingen, D. \& van Embden, J. D. A. (1996). Characterization of the catalase-peroxidase gene $(k a t G)$ and inhA locus in isoniazidresistant and -susceptible strains of Mycobacterium tuberculosis by automated DNA sequencing: restricted array of mutations associated with drug resistance. J Infect Dis 173, 196-202.

Parish, T. \& Stoker, N. G. (1997). Development and use of a conditional antisense mutagenesis system in mycobacteria. FEMS Microbiol Lett 154, 151-157.

Pascopella, L., Collins, F. M., Martin, J. M., Lee, M. H., Hatfull, G. F., Stover, C. K., Bloom, B. R. \& Jacobs, W. R. (1994). Use of in vivo complementation in Mycobacterium tuberculosis to identify a genomic fragment associated with virulence. Infect Immun 62, 1313-1319.

Quemard, A., Sacchettini, J. C., Dessen, A., Vilcheze, C., Bittman, R., Jacobs, W. R. \& Blanchard, J. S. (1995). Enzymatic characterization of the target for isoniazid in Mycobacterium tuberculosis. Biochemistry 34, 8235-8241.

Quemard, A., Dessen, A., Sugantino, M., Jacobs, W. R., Sacchettini, J. C. \& Blanchard, J. S. (1996). Binding of catalaseperoxidase-activated isoniazid to wild-type and mutant $\mathrm{Myco}$ bacterium tuberculosis enoyl-ACP reductases. J Am Chem Soc 118, 1561-1562.

Rapaport, E., Levina, A., Metelev, V. \& Zamecnik, P. C. (1996). Antimycobacterial activities of antisense oligodeoxynucleotide phosphorothioates in drug-resistant strains. Proc Natl Acad Sci USA 93, 709-713.

Reyrat, J., Berthet, F. \& Gicquel, B. (1995). The urease locus of Mycobacterium tuberculosis and its utilization for the demonstration of allelic exchange in Mycobacterium bovis bacillus Calmette-Guerin. Proc Natl Acad Sci USA 92, 8768-8772.

Rouse, D. A., Li, Z., Bai, G. \& Morris, S. L. (1995). Characterization of the $k a t G$ and $i n b A$ genes of isoniazid-resistant clinical isolates of Mycobacterium tuberculosis. Antimicrob Agents Chemother 39, 2472-2477.

Sherman, D. R., Sabo, P. J., Hickey, M. J., Arain, T. M., Mahairas, G. G., Yuan, Y., Barry, C. E., III \& Stover, C. K. (1995). Disparate responses to oxidative stress in saprophytic and pathogenic mycobacteria. Proc Natl Acad Sci USA 92, 6625-6629.

Sherman, D. R., Mdluli, K., Hickey, M. J., Arain, T. M., Morris, S. L. \& Barry, C. E. (1996). Compensatory ahpC gene expression in isoniazid-resistant Mycobacterium tuberculosis. Science 272, 1641-1643.

van Soolingen, D., Hermans, P. W. M., de Haas, P. E. W., Soll, D. R. \& van Embden, J. D. A. (1991). Occurrence and stability of insertion sequences in Mycobacterium tuberculosis complex strains: evaluation of an insertion sequence-dependent DNA polymorphism as a tool in the epidemiology of tuberculosis. J Clin Microbiol 29, 2578-2586.

Sreevatsan, S., Pan, X., Zhang, Y., Deretic, V. \& Musser, J. M. (1997). Analysis of the $o x y R-a b p C$ region in isoniazid-resistant and -susceptible Mycobacterium tuberculosis complex organisms recovered from diseased humans and animals in diverse localities. Antimicrob Agents Chemother 41, 600-606.

Steenken, W. \& Wolinsky, E. (1955). Studies on the pathogenicity of several INH-resistant cultures in mice, guinea pigs and rabbits. 
In Transactions of the 14th Veterans Administration Conference on the Chemotherapy of Tuberculosis, pp. 210-217. Washington, DC: US Veterans Administration.

Storz, G., Jacobson, F. S., Tartaglia, L. A., Morgan, R. W., Silveira, L. A. \& Ames, B. N. (1989). An alkyl hydroperoxide reductase induced by oxidative stress in Salmonella typhimurium and Escherichia coli: genetic characterization and cloning of ahp. J Bacteriol 171, 2049-2055.

Telenti, A., Honore, N., Bernasconi, C., March, J., Ortega, A., Heym, B., Takiff, H. E. \& Cole, S. T. (1997). Genotype assessment of isoniazid and rifampin resistance in Mycobacterium tuberculosis: a blind study at reference laboratory level. J Clin Microbiol 35, 719-723.

Wagner, E. G. H. \& Simons, R. W. (1994). Antisense RNA control in bacteria, phages and plasmids. Annu Rev Microbiol 48, 713-742.

Wards, B. J. \& Collins, D. M. (1996). Electroporation at elevated temperatures substantially improves transformation efficiency of slow growing mycobacteria. FEMS Microbiol Lett 145, 101-105.
Wilson, T. M. \& Collins, D. M. (1996). ahpC, a gene involved in isoniazid resistance of the Mycobacterium tuberculosis complex. Mol Microbiol 19, 1025-1034.

Wilson, T. M., de Lisle, G. W. \& Collins, D. M. (1995). Effect of inhA and $k a t G$ on isoniazid resistance and virulence of $\mathrm{Myco-}$ bacterium bovis. Mol Microbiol 15, 1009-1015.

Zhang, Y. \& Young, D. (1994). Strain variation in the kat $G$ region of Mycobacterium tuberculosis. Mol Microbiol 14, 301-308.

Zhang, Y., Garbe, T. \& Young, D. (1993). Transformation with $k a t G$ restores isoniazid-sensitivity in Mycobacterium tuberculosis isolates resistant to a range of drug concentrations. Mol Microbiol 8, 521-524.

Zhang, Y., Dhandayuthapani, S. \& Deretic, V. (1996). Molecular basis for the exquisite sensitivity of Mycobacterium tuberculosis to isoniazid. Proc Natl Acad Sci USA 93, 13212-13216.

Received 26 March 1998; revised 26 June 1998; accepted 7 July 1998. 